\title{
EFFECTIVENESS OF IDENTIFIED JAVANESE TURMERIC ETHANOL EXTRACT FOR THE INHIBITION OF BIOFILM FORMATION BY STREPTOCOCCUS MUTANS AND PORPHYROMONAS GINGIVALIS
}

\author{
LIZA NOAH FEBRIANA MARPAUNG, DEWI FATMA SUNIARTI*, AGOENG TJAHAJANI SARWONO
}

Department of Oral Biology, Faculty of Dentistry, Universitas Indonesia, Jakarta 10430, Indonesia. E-mail: dewisuniarti@yahoo.com Received 01 October 2018, Revised and Accepted 19 February 2019

\section{ABSTRACT}

Objective: To study the effectiveness of identified Javanese turmeric ethanol extract (IJTEE) against single and combined biofilm formation by Streptococcus mutans and Porphyromonas gingivalis.

Methods: S. mutans ATCC 25175 and P. gingivalis ATCC 33277 were tested for the minimum inhibitory concentration (MIC) and minimum bactericidal concentration (MBC) of IJTEE using microdilution technique. The inhibition of biofilm formation by IJTEE was analyzed using crystal violet assay.

Results: MIC and MBC of IJTEE for S. mutans were 5\% and 15\%, respectively. MIC of IJTEE for the biofilm of S. mutans was $1 \%$ and for that of P. gingivalis was $15 \%$; the MIC of IJTEE for the combined biofilm was $0.5 \%$.

Conclusion: IJTEE was effective in inhibiting single and combined biofilm formation by S. mutans and P. gingivalis.

Keywords: Biofilm, identified Javanese turmeric ethanol extract, Minimum bactericidal concentration, Minimum inhibitory concentration, Porphyromonas gingivalis, Streptococcus mutans.

(C) 2019 The Authors. Published by Innovare Academic Sciences Pvt Ltd. This is an open access article under the CC BY license (http://creativecommons. org/licenses/by/4. 0/) DOI: http://dx.doi.org/10.22159/ijap.2019.v11s1.156

\section{INTRODUCTION}

Indonesia is a nation rich in mega-biodiversity where there are 40,000 endemic plants and 6000 of them are used for herbal medication [1]. Indonesian people use the medicinal plants for self-medication; however, these plants are not prescribed by doctors because no research has been conducted to identify their efficacy; their safety is also unclear [2,3]. Curcuma xanthorrhiza Roxb. (Javanese turmeric) is one of the medicinal plants that may be developed as phytopharmaca because some research has identified its effectiveness in relieving some pathological conditions (e.g., liver disease, rheumatic disease, fatigue, and depression). It also has antibacterial, antifungal, antioxidant, and antitumor effects [4]. Xanthorrhizol is known as one of the active compounds in Javanese turmeric and Atsiri oil that has an antibacterial effect against several pathogens in the oral cavity [5].

Bacteria are normal microorganisms found in the oral cavity, but they become pathogenic once they interact with other bacteria within the biofilm. Caries is a disease of the oral cavity and is often caused by Streptococcus mutans [6] that form a biofilm. Biofilm formation is initiated by interaction (quorum sensing) between planktonic early colonizing bacteria and the enamel surface of the teeth. After the biofilm is formed, it binds to Gram-negative anaerobic late colonizing bacteria (Porphyromonas gingivalis), leading to periodontal disease [7].

A synthetic antibacterial drug, chlorhexidine gluconate $(\mathrm{CHx})$, having a broad spectrum of action against pathogenic bacteria in the oral cavity, has been formulated to prevent caries and periodontal diseases. $\mathrm{CHx}$ decreases pellicle formation and inhibits bonding between bacteria and the surface of the teeth. This drug is not yet widely available because it causes many side effects, one of which is biofilm retention [8]. People in Indonesia experience difficulty accessing synthetic drugs because of the lack of effective distribution. Many people use Javanese turmeric to treat diseases. The antibacterial effect of Javanese turmeric is known to result from the component xanthorrhizol, but the composition has not been established. In previous research, xanthorrhizol isolated from Javanese turmeric has been used against planktonic bacteria such as $S$. mutans and P. gingivalis [9], but further research is needed to identify their effectiveness in inhibiting biofilm formation by $S$. mutans and $P$. gingivalis. This study aimed to evaluate the effectiveness of identified Javanese turmeric ethanol extract (IJTEE) in inhibiting single or combined biofilm formation by $S$. mutans and P. gingivalis.

\section{METHODS}

This study obtained test materials in the form of Javanese turmeric ethanol extract from Balittro, Bogor. The ethanol extract of Javanese turmeric was centrifuged ( $3000 \mathrm{rpm} ; 20 \mathrm{~min} ; 37^{\circ} \mathrm{C}$ ), and the top layer was used for identification and later referred as IJTEE. IJTEE was diluted with $10 \%$ dimethyl sulfoxide to obtain $0.25 \%, 0.5 \%, 1 \%, 5 \%$, $10 \%, 15 \%, 20 \%$, and $25 \%$ concentrations of IJTEE solution, according to the dilution formula $\mathrm{C} 1 \times \mathrm{V} 1=\mathrm{C} 2 \times \mathrm{V} 2$.

Next, 10- $\mu \mathrm{l}$ samples of each bacterium were obtained from the stock of the Oral Biology Laboratory, University of Indonesia, and inserted into brain-heart infusion (BHI) jelly, and incubated in an anaerobic atmosphere, $48 \mathrm{~h}$ for $S$. mutans and $72 \mathrm{~h}$ for P. gingivalis. One resulting colony of each bacterium was inserted into a microcentrifuge tube containing $1 \mathrm{ml}$ phosphate-buffered saline (PBS), and the tube was centrifuged $\left(13,000 \mathrm{rpm} ; 60 \mathrm{~s} ; 40^{\circ} \mathrm{C}\right)$. The supernatant solution was removed from the tube, so that only a pellet layer remained inside the microcentrifuge tube; then, $1 \mathrm{ml}$ of BHI broth was added to the tube, and the contents were homogenized by means of vortex.

Different dilutions of the bacteria-BHI jelly ratio from 10:1 to 10:8 were prepared, and the numbers of bacterial colonies in each dilution were calculated. From the results of the bacterial colony count, a bacteria-BHI jelly ratio of 10:5 was used as the sample because the number of bacterial colonies at this ratio was sufficient. 
Determination of minimum inhibitory concentration and minimum bactericidal concentration

In total, $100 \mu \mathrm{l}$ of each of the $10: 5$ bacteria-BHI jelly samples was inserted into three types of wells, designated treatment, negative control, and positive control. A 100- $\mu$ l serial concentration of IJTEE was added to the treatment wells; $100 \mu \mathrm{l}$ of BHI broth alone was added to the negative control wells; and $100 \mu \mathrm{l}$ of $0.2 \% \mathrm{CHx}$ was added to the positive control wells. In addition, a "blank" plate of wells with $100 \mu \mathrm{l}$ of BHI broth and $100 \mu \mathrm{l}$ of test material was prepared. Then, the plates were incubated in an anaerobic atmosphere at $37^{\circ} \mathrm{C}$ for $2 \times 24 \mathrm{~h}$ for $S$. mutans and $3 \times 24$ h for P. gingivalis. The optical density absorbance value was read by a microplate reader at a wavelength of $450 \mathrm{~nm}$ [10].

Test for the effectiveness of identified Javanese turmeric ethanol extract in inhibiting single biofilm

We prepared a BHI broth medium to which $0.2 \%$ sucrose was added. Then, each bacterium sample was diluted using the same steps as before until the bacterium-BHI jelly ratio was 10:5

Well plates labeled with the sample name were prepared. Then, $100-\mu \mathrm{l}$ suspension of each of the bacteria was added into the treatment wells, the negative control wells, and the positive control wells. Then, the treatment sample was exposed to serial concentrations of IJTEE as high as $100 \mu \mathrm{l}$. In the positive control wells, $100 \mu \mathrm{l}$ of $0.2 \% \mathrm{CHx}$ was added; in the negative control wells, $100 \mu \mathrm{l}$ of BHI broth $(0.2 \%$ sucrose $)$ was added. In addition, a "blank" plate of wells containing $100 \mu \mathrm{l}$ of BHI broth medium (with $0.2 \%$ sucrose) and $100 \mu$ of the test material was prepared. Then, each well plate was incubated in an anaerobic atmosphere at $37^{\circ} \mathrm{C}$ for $18 \mathrm{~h} \mathrm{[11].}$

Test for the effectiveness of identified Javanese turmeric ethanol extract in inhibiting the combined biofilm

BHI broth medium ( $0.2 \%$ sucrose) was prepared with $1 \mathrm{ml}$ vitamin $\mathrm{K}$. Then, the bacteria were diluted using the same steps as before until the bacteria-BHI jelly ratio was 10:5

Following this, $50 \mu \mathrm{l}$ of the 10:5 S. mutans suspension solution and $50 \mu$ of the 10:5 P. gingivalis suspension solution were added to each well. From each treatment well, $100 \mu \mathrm{l}$ was exposed to various concentrations. In the positive control wells, $100 \mu \mathrm{l}$ of $0.2 \% \mathrm{CHx}$ was added; in the negative control wells, $100 \mu \mathrm{l}$ of BHI broth was added. In addition, a "blank" well plate of wells containing $100 \mu \mathrm{l}$ of BHI broth and $100 \mu \mathrm{l}$ of test material was prepared. Each well plate was then incubated in an anaerobic atmosphere at $37^{\circ} \mathrm{C}$ for $18 \mathrm{~h}$ [8]

\section{Crystal violet test}

The solution in each well was aspirated, rinsed with $200 \mu \mathrm{l}$ of PBS solution, fixed for $10 \mathrm{~min}$, and then stained with $0.5 \%$ crystal violet solution. To obtain a $0.5 \%$ crystal violet solution, a centrifuge tube containing $49.75 \mathrm{ml}$ aquadest was prepared with $0.25 \mathrm{ml}$ of crystal violet solution. Later, $200 \mu \mathrm{l}$ of crystal violet solution was added into each well, and the plates were incubated at $37^{\circ} \mathrm{C}$ for $15 \mathrm{~min}$. Then, the solution in each well was rinsed twice with sterile distilled water, $200 \mu \mathrm{l}$ of $96 \%$ ethanol was added, and the plates were incubated at $37^{\circ} \mathrm{C}$ for $15 \mathrm{~min}$; the plates were inserted into the microplate reader set at 490-nm wavelength to obtain optical density [11,12].

Data results of the inhibition test of biofilm formation were subjected to analysis of variance (ANOVA), bivariate correlation, and linear regression to identify the relationship between the various substances and the amount of biofilm.

\section{RESULTS}

The minimum inhibitory concentration (MIC) of IJTEE against S. mutans was $5 \%$, and the MBC of IJTEE against $S$. mutans was $15 \%$. However, MIC and MBC against $P$. gingivalis could not be established because no inhibition of P. gingivalis exceeded 90\% (Table 1).

Fig. 1 shows the effectiveness of IJTEE in inhibiting the formation of S. mutans biofilms starting at a concentration of $1 \%$, so that the $\mathrm{MBEC}_{50}$ of $S$. mutans was set at a concentration of $1 \%$. One-way ANOVA showed significant differences $(\mathrm{p}<0.05)$ between the treatment samples and the negative and positive control samples. The bivariate correlation test between IJTEE concentration and biofilm inhibition percentage showed an increase in IJTEE concentration with increased biofilm inhibition $(\mathrm{p}<0.025)$. The linear regression test showed the closeness of the relationship $\left(\mathrm{R}^{2}=0.79\right)$ between biofilm inhibition percentage and IJTEE concentration. $79 \%$ inhibition of biofilm formation was estimated to be caused by IJTEE, whereas $21 \%$ inhibition of biofilm formation was caused by other factors (the number of bacteria that could not be ascertained in each treatment sample). The regression formula obtained was as follows:

$$
Y=48.75+2.41(x)
$$

This proved the existence of linear regression between IJTEE and inhibition of biofilm formation. With every change in concentration, the inhibition of biofilm increased by $2.416 \%$.

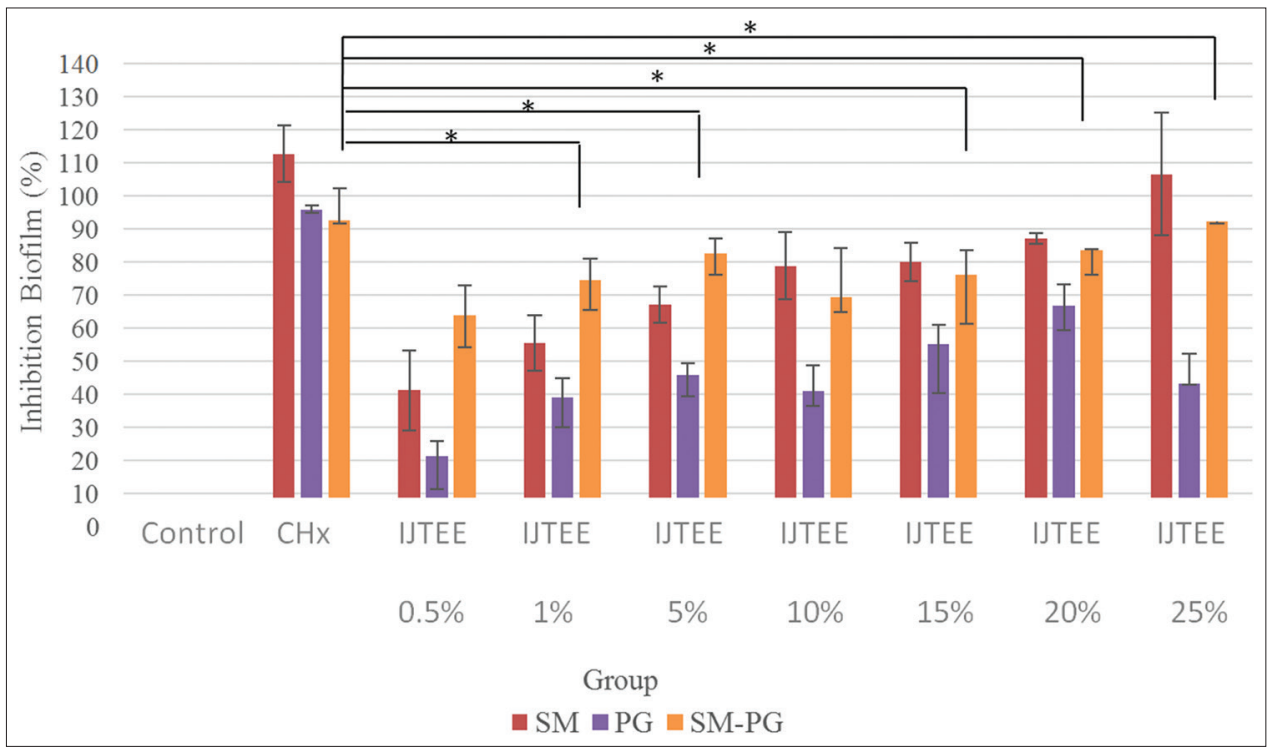

Fig. 1: Effectiveness of IJTEE in inhibiting biofilm formation. Abbreviations: IJTEE: Identified Javanese turmeric ethanol extract, CHx: Chlorhexidine gluconate, PG: Porphyromonas gingivalis, SM: Streptococcus mutans 
Table 1: The percentage inhibition of Streptococcus mutans and Porphyromonas gingivalis by different concentrations of identified Javanese turmeric ethanol extract

\begin{tabular}{|c|c|c|}
\hline \multirow[t]{2}{*}{ Sample } & \multicolumn{2}{|l|}{ Inhibition $(\%) \pm S D$} \\
\hline & $\begin{array}{l}\text { Streptococcus } \\
\text { mutans* }\end{array}$ & $\begin{array}{l}\text { Porphyromonas } \\
\text { gingivalis* }\end{array}$ \\
\hline Negative control & 0 & 0 \\
\hline Positive control & $100.19 \pm 0.94$ & $101.88 \pm 2.17$ \\
\hline IJTEE $0.25 \%$ & $85.84 \pm 1.52$ & $65.02 \pm 6.25$ \\
\hline IJTEE 0.5\% & $86.74 \pm 1.45$ & $81.38 \pm 2.33$ \\
\hline IJTEE 1\% & $89.42 \pm 2.21$ & $71.71 \pm 9.79$ \\
\hline IJTEE 5\% & $92.85 \pm 1.00$ (MIC) & $75.72 \pm 2.95$ \\
\hline IJTEE 10\% & $95.17 \pm 2.59$ & $84.46 \pm 3.48$ \\
\hline IJTEE 15\% & $100.48 \pm 0.67(\mathrm{MBC})$ & $79.8 \pm 2.57$ \\
\hline IJTEE 20\% & $100.57 \pm 0.20$ & $79.32 \pm 3.61$ \\
\hline IJTEE 25\% & $100.23 \pm 0.02$ & $82.25 \pm 2.46$ \\
\hline $10 \%$ DMSO solution & $16.51 \pm 2.14$ & $13.41 \pm 3.93$ \\
\hline
\end{tabular}

${ }^{*} n=2$. DMSO: Dimethyl sulfoxide, IJTEE: Identified Javanese turmeric ethanol extract, MBC: Minimum bactericidal concentration, MIC: Minimum inhibitory concentration, SD: Standard deviation

The effectiveness of IJTEE in inhibiting the formation of biofilm by P. gingivalis started at a concentration of $15 \%$, so that $\mathrm{MBEC}_{50}$ of $P$. gingivalis was defined at the concentration of $15 \%$. One-way ANOVA showed significant differences $(\mathrm{p}<0.05)$ between treatment samples and negative and positive control samples. The bivariate correlation test between IJTEE concentration and biofilm inhibition percentage showed an increase in IJTEE concentration with increased biofilm inhibition $(p<0.025)$. The linear regression test showed the closeness of the relationship $\left(R^{2}=0.36\right)$ between biofilm inhibition percentage and IJTEE concentration. In addition, it is indicated that $36 \%$ inhibition of biofilm formation was caused by IJTEE, and $64 \%$ inhibition of biofilm formation was caused by other factors (the formation of older [24-h] $P$. gingivalis biofilms). The regression formula obtained was as follows:

$$
Y=33.95+0.96(x)
$$

This formula shows the closeness of the relationship between IJTEE and inhibition of biofilm formation. With every change in concentration, the inhibition of biofilm increased by $0.96 \%$

The effectiveness of IJTEE in inhibiting the formation of combined biofilm by $S$. mutans and $P$. gingivalis was started at a concentration of $0.5 \%$, so that the MBEC $_{50}$ of the combination of $S$. mutans and $P$ gingivalis was at the concentration of $0.5 \%$. One-way ANOVA showed a significant difference $(\mathrm{p}<0.05)$ between the treatment samples and negative control samples, but not between the treatment samples and positive control samples ( $p>0.05)$. The bivariate correlation test between IJTEE concentration and biofilm inhibition percentage showed an increase in IJTEE concentration with increased biofilm inhibition $(p<0.025)$. The linear regression test showed the closeness of the relationship $\left(\mathrm{R}^{2}=0.34\right)$ between biofilm inhibition percentage and IJTEE concentration. In the result of bivariate correlation test between IJTEE concentration and inhibition of biofilm formation, correlation coefficient value was 0.58 , indicating a positive correlation. In addition, $\mathrm{R}^{2}(0.34)$ indicated that $34 \%$ inhibition of biofilm formation was caused by IJTEE, and $66 \%$ inhibition of biofilm formation was caused by other factors. The regression formula obtained was as follows:

$$
Y=69.25+0.74(x)
$$

This formula showed the closeness of the relationship between IJTEE and inhibition of biofilm formation. With every change in concentration, the inhibition of biofilm increased by $0.74 \%$.

\section{DISCUSSION}

IJTEE has different antibacterial activities against $S$. mutans and P. gingivalis, presumably because of differences in cell wall. S. mutans have thick cell walls consisting of peptidoglycan (50-90\%), whereas $P$ gingivalis has cell walls composed of a thin layer of peptidoglycan and an additional outer membrane composed of lipids, with a periplasmic space between. In addition, the composition of the bacterial wall of $P$. gingivalis is more complex because lipopolysaccharide senses before a foreign object penetrates the cell, and hydrophobic porin lipoprotein then limits the diffusion of foreign matter into the cell. Further research is needed to determine the MIC and MBC of IJTEE against $P$. gingivalis. Our findings can also be compared with those of previous research in which MIC and MBC of IJTEE against $S$. mutans were identified [13]. Determinations of MIC may differ as a result of the difference in extracts used due to the selection of raw materials that cause the xanthorrhizol levels to be different. The MIC and MBC values of $P$. gingivalis that cannot be determined may be similar to those of previous studies although the solvents used in this study are different [14].

The effectiveness of identified Javanese turmeric ethanol extract in inhibiting the biofilm formation by $S$. mutans

ANOVA showed significant differences $(\mathrm{p}<0.05)$ between treatment samples and negative and positive control samples. We suspected that IJTEE had an effect on inhibiting the formation of biofilm by $S$. mutans, but its effectiveness was not equivalent to that of $\mathrm{CHx}$. This suspicion is supported by previous research, in which $\mathrm{CHx}$ had strong antibacterial effects in penetrating biofilm extracellular matrix. In addition, S. mutans has a simple peptidoglycan cell wall, which can be easily penetrated by antibacterial agents [8].

The effectiveness of identified Javanese turmeric ethanol extract in inhibiting biofilm formation by Porphyromonas gingivalis Fig. 1 shows that, at IJTEE concentrations of $15 \%$ and $20 \%$, the formation of biofilm by $P$. gingivalis was inhibited; therefore, we can conclude that there was antibacterial activity. It may be caused by xanthorrhizol and flavonoids contained in IJTEE that have antibacterial effects. Meanwhile, at IJTEE concentrations of $15 \%$ and $20 \%$, the degree of inhibition of $P$. gingivalis biofilm formation did not reach more than $90 \%$. This finding and results of previous studies indicate that antibacterial agents inhibit the formation of biofilms at lower MICs, and antibacterial activity of xanthorrhizol inhibits the formation of biofilm by P. gingivalis at higher concentrations [5].

ANOVA showed significant differences $(\mathrm{p}<0.05)$ between the treatment samples and negative and positive control samples. We suspect that IJTEE has an effect on inhibiting the formation of biofilm by P. gingivalis, but its effectiveness was not equivalent to that of $\mathrm{CHx}$, which has a strong antibacterial effect in penetrating the biofilm extracellular matrix. In addition, $P$. gingivalis has a more complex cell wall that can limit the diffusion of foreign matter into cells [13].

The effectiveness of identified Javanese turmeric ethanol extract in inhibiting combined biofilm formation by Streptococcus mutans and Porphyromonas gingivalis

Fig. 1 shows the inhibition of the formation of combined biofilm by $S$. mutans and $P$. gingivalis by IJTEE occurred at concentrations of $0.5 \%$ and increased with increasing IJTEE concentrations. This effect may have been caused by xanthorrhizol and flavonoids contained in IJTEE that have antibacterial effects. This is supported by previous research which stated that IJTEE was able to decrease biofilm viability [13]

The ANOVA test between the treatment sample and the negative control sample showed a significant difference $(\mathrm{p}<0.05)$, and the positive control sample showed no significant difference $(p>0.05)$. It is suspected that IJTEE had an effect on inhibiting the formation of combined biofilm by $S$. mutans and P. gingivalis, and the effectiveness of IJTEE was equivalent to $\mathrm{CHx}$. The interactions between bacteria may play a role in inhibiting biofilm formation [15]. It is presumed that quorum sensing between bacteria causes antibacterial agents to be more effective. This is supported by previous research, wherein $P$. gingivalis inhibited quorum sensing among $S$. mutans, and therefore, S. mutans failed to interact [15]. 


\section{CONCLUSION}

IJTEE effectively inhibited the formation of biofilm by S. mutans starting at a concentration of $1 \%$ and the formation of biofilm by P. gingivalis starting at a concentration of 15\%; it inhibited the combined biofilm formation by S. mutans and P. gingivalis starting at a concentration of $0.5 \%$.

\section{CONFLICT OF INTEREST}

The authors report no conflict of interest.

\section{REFERENCES}

1. Maryanto I, Rahajoe JS, Munawar SS, Dwiyanto W, Asikin D, Ariati SR, et al. Bioresources for green economics development. Jakarta: LIPI Press; 2013. p. 3-8.

2. Nugraha AS, Keller PA. Revealing indigenous Indonesian traditional medicine: Anti-infective agents. Nat Prod Commun 2011;6:1953-66.

3. Dewoto HR. The development of Indonesian herbal medicine as phytopharmacy. Maj Kedokt Indones 2007;57:205-11

4. Hayani E. Analysis of Chemical Contents in Javanese Turmeric. Jakarta: Pusat Penelitian dan Pengembangan Pertanian; 2006. p. 309-12.

5. Hwang JK, Shim JS, Pyun YR. Antibacterial activity of xanthorrhizol from Curcuma xanthorrhiza against oral pathogens. Fitoterapia 2000;71:321-3

6. Metwalli KH, Khan SA, Krom BP, Jabra-Rizk MA. Streptococcus mutans, Candida albicans, and the human mouth: A sticky situation.
PLoS Pathog 2013;9:e1003616.

7. Marsh PD, Martin MV. Oral Microbiology. $5^{\text {th }}$ ed. Philadelphia, PA: Churchill Livingstone; 2009. p. 8-103.

8. Solmaz G, Korachi M. Inhibition and disruption properties of chlorhexidine gluconate on single and multispecies oral biofilms. Jundishapur J Microbiol 2013;6:61-6.

9. Lee LY, Shim JS, Rukayadi Y, Hwang JK. Antibacterial activity of xanthorrhizol isolated from Curcuma xanthorrhiza Roxb. Against foodborne pathogens. J Food Prot 2008;71:1926-30.

10. Hertiani T, Pratiwi S. Effect of Indonesian medicinal plants essential oils on Streptococcus mutans biofilm. Maj Farm Indones 2011;22:174-81.

11. A Algarni A, H Yassen G, L Gregory R. Inhibitory effect of gels loaded with a low concentration of antibiotics against biofilm formation by Enterococcus faecalis and Porphyromonas gingivalis. J Oral Sci 2015;57:213-8.

12. Suwandi T, Suniarti DF, Prayitno SW. Effect of ethanol extract of Hibiscus sabdariffa L. calyx on Streptococcus sanguinis viability in vitro biofilm based on crystal violet. J Med Plants Res 2013;7:2476-82.

13. Busri A. Antibacterial Effect of Javanese turmeric Ethanol Extract on the Dual Species of Streptococcus mutans and Streptococcus sanguinis (in vitro). Undergraduate Thesis. Jakarta: Universitas Indonesia; 2013.

14. Mangunwardoyo W, Usia TD. Antimicrobial and identification of active compound Curcuma xanthorrhiza Roxb. Int J Basic Appl Sci 2012;12:69-78.

15. Tu Y, Ling X, Chen Y, Wang Y, Zhou N, Chen H. The supernatans of S. mutans and S. sanguinis significantly inhibit the growth and biofilm formation P. gingivalis. Med Sci Monit 2017;23:5439-45. 